\title{
Fetal Poisoning after Maternal Paraquat Ingestion During Third Trimester of Pregnancy: Case Report and Literature Review
}

\author{
Chulathida Chomchai, $M D^{a, b}$, Anongrat Tiawilai, $M D^{c}$ \\ aAssociate Professor of Pediatrics, Division of Ambulatory Pediatrics and Pediatric Toxicology, Department of Pediatrics, Siriraj \\ Hospital \\ bFaculty of Medicine, Mahidol University \\ cPotharam Hospital, Ministry of Public Health, Photaram, Rachaburi, Thailand
}

\begin{abstract}
Introduction: Paraquat remains one of the common substances involved in intentional ingestions in Thailand. However, data on outcomes of paraquat ingestion during pregnancy is rarely available and the management is controversial.

Case report: A 17-year-old female in 36+ weeks of gestation attempted suicide by ingesting $1 / 2$ a glass of Gramozone ${ }^{\mathrm{TM}}$ (paraquat $27.6 \% \mathrm{w} / \mathrm{v}) 5$ hours prior to arrival to the hospital. Gastric aspiration and lavage was performed and she was given $50 \mathrm{~g}$ of activated charcoal and $150 \mathrm{~g}$ of Fuller's Earth suspension. A male infant, weighing 2,390 g with an Apgar score of $7^{1} 10^{10}$, was delivered via emergency caesarean section 7 hours after ingestion. Due to presence of paraquat in the gastric lavage fluid, the mother was placed on dexamethasone/cyclophosphamide therapy. She developed mild renal insufficiency 63 hours after the ingestion. The infant developed tachypnea immediately after birth that self-resolved. The infant developed tachypnea again on day 6 of life. A chest x-ray revealed right lower lobe infiltration that progressed to diffuse interstitial pattern; subsequent chest x-rays showed evidence of fibrosis. Both mother and infant survived and the infant was discharged and sent home with oxygen 0.5 LPM. Upon follow up at 10 months of age, he still had evidence of chronic lung disease clinically and on chest x-ray.
\end{abstract}

Conclusion: Paraquat ingestion during the third trimester of pregnancy usually carries a very poor prognosis. Review of reported literature suggests that this case report represents only the second survival of mother and child.

\section{INTRODUCTION}

Self-poisoning with paraquat is considered one of the most serious ingestions seen in Thailand. According to the report by the Ramathibodi Poison Center Toxic Exposure Surveillance System, paraquat is the ingested substance in $20-25 \%$ of all reported pesticide poisonings and accounts for $20 \%$ of the overall poisoning mortalities seen in Thailand between the years 2000 and 2003 [1]. Although there are numerous articles addressing management and outcomes of paraquat poisoning in international medical literature, few of these involve pregnant women and their fetus. We are reporting a case of intentional paraquat ingestion in a pregnant female. A review of reported cases is also included.

Keywords: paraquat, neonatal exposure, poisoning, fetus, transplacental, herbicide

Notes: There was no outside funding of any kind used for this study.

Acknowledgements: The authors would like to thank Clinical Professor Kent Olson, Medical Director of the San Francisco Poison Control Center for his reviews and comments of this case.

Corresponding Author: Chulathida Chomchai, Department of Pediatrics, Siriraj Hospital 2 Prannok Road, Bangkok Noi, Bangkok 10700, Thailand. Email: sicgt@mahidol.ac.th 


\section{CASE REPORT}

A 17-year-old pregnant female presented at $36+$ weeks gestational age with a history of paraquat ingestion. Her sister reported that the patient attempted to commit suicide by taking 2 mouthfuls (about 30ml) of Gramozone ${ }^{\mathrm{TM}}$ (paraquat dichloride 27.6\% w/v) 5 hours prior to presentation at the hospital. The patient had had no prior prenatal care. On initial evaluation the body weight was $45 \mathrm{~kg}$, the heart rate was 82 beats $/ \mathrm{min}$, respirations were 22 per minute, and the blood pressure was $130 / 90 \mathrm{~mm} \mathrm{Hg}$. Oxygen saturation was $98 \%$ on room air.

The patient was alert and oriented. There were visible burns on the lips. Heart and lung examination was unremarkable. Abdominal examination revealed a third trimester pregnancy with uterine height consistent with the estimated gestational age. A neurological examination was within normal limits. Initial laboratory tests included a white blood count of 19,200 cells/uL (94\% neutrophils, $6 \%$ lymphocytes), a hemoglobin of $9.9 \mathrm{gm} / \mathrm{dL}$, a hematocrit of $31 \%$, and platelets at $225,000 / \mathrm{uL}$. Serum sodium was $148 \mathrm{mmol} / \mathrm{L}$, potassium $4.7 \mathrm{mmol} / \mathrm{L}$, chloride $111 \mathrm{mmol} / \mathrm{L}$, total CO2 $36 \mathrm{mml} / \mathrm{L}$, BUN $14 \mathrm{mg} / \mathrm{dL}$, and creatinine was $0.9 \mathrm{mg} / \mathrm{L}$.

Gastric aspiration and lavage was performed in the emergency room and yielded bluish-tinged liquid. A 50-gram dose of activated charcoal was given orally, followed by 150 grams of Fuller's Earth solution. An emergency obstetric consultation was obtained, along with a toxicology consultation, to evaluate the impact of the ingestion on the fetus.

A prenatal ultrasound showed intrauterine singleton pregnancy with the fetus in cephalic presentation. None Stress Test was reactive and fetal heart sounds were audible with a rate of approximately 140 beats $/ \mathrm{min}$.

Due to the seriousness of the ingestion and the fact that paraquat can readily cross the placenta, an emergency cesarean section was performed.

A male infant, weighing $2,390 \mathrm{~g}$, was born via cesarean section approximately 7 hours after the ingestion. Apgar scores were $7^{1}$ and $10^{5}$. The amniotic fluid was clear. His head circumference was $32 \mathrm{~cm}$ and length was $46 \mathrm{~cm}$. The infant received positive pressure ventilation for a heart rate of $100 \mathrm{bpm}$, and the heart rate readily increased to $120 \mathrm{bpm}$, and the child was transferred to the normal newborn nursery for further observation.

\section{Hospital course of mother}

Due to the presence of paraquat in the gastric lavage fluid, the mother was started on intravenous dexamethasone $10 \mathrm{mg}$ every 6 hours and cyclophosphamide $80 \mathrm{mg}$ intravenously every 8 hours. At 63 hours after ingestion, blood chemistries showed an elevation of blood urea nitrogen at $18 \mathrm{mg} / \mathrm{dL}$ and creatinine at $1.5 \mathrm{mg} / \mathrm{dL}$; which normalized at 8 days post ingestion. The liver enzymes and liver function tests remained normal.

The patient completed a 14-day course of dexamthasone/ cyclophosphamide and was discharged home.

\section{Hospital course of infant}

The infant was noted to have mild tachypnea and was briefly observed in the nursery where his tachypnea resolved over 24 hours. His chest x-ray at that time was unremarkable. A toxicology consultation was obtained at that time and it was decided that a prophylactic course of dexamethasone/cyclophosphamide regimen would not be beneficial at this time.

At day 6 of life, the infant developed worsening tachypnea with subcostal retractions. Auscultation was normal. A chest X-ray showed a right lower lobe infiltrate (Figure 1). The patient was started on penicillin and gentamicin for presumed pneumonia. Over the next 4 days, his respiratory status worsened. His respiratory rate was between 100-125 times per minute, and he was given 2 liters of supplemental oxygen via a nasal cannula to maintain saturation between $85-90 \%$. The antibiotics were changed to cefotaxime and amikacin for broader coverage. His chest $\mathrm{x}$-ray showed a progressively more diffuse interstitial pattern (Figure 2). Although he was unable to be weaned off of oxygen at the time of discharge, his symptoms gradually improved, and the rest of the patient's clinical course was unremarkable. He completed a 14-day course of cefotaxime/amikacin. His chest $\mathrm{x}$-ray prior to discharge showed only minimum interstitial infiltrate (Figure 3 ). The patient was hospitalized for a total of 22 days and went home on oxygen cannula at 0.5 LPM. Upon follow up, the infant continued to demonstrate signs of chronic lung disease characterized by recurrent wheezing, tachypnea, and hypoxia. At 10 months of age, he was weaned off of home oxygen therapy. Subsequently, he had several episodes of wheezing related to respiratory illnesses, but his symptoms significantly improved by the time he was 16 -months-old.

\section{DISCUSSION}

Paraquat (1,1'-dimethyl-4,4'-bipyridylium dichloride) is a popular non-seletive, contact herbicide used in developing countries

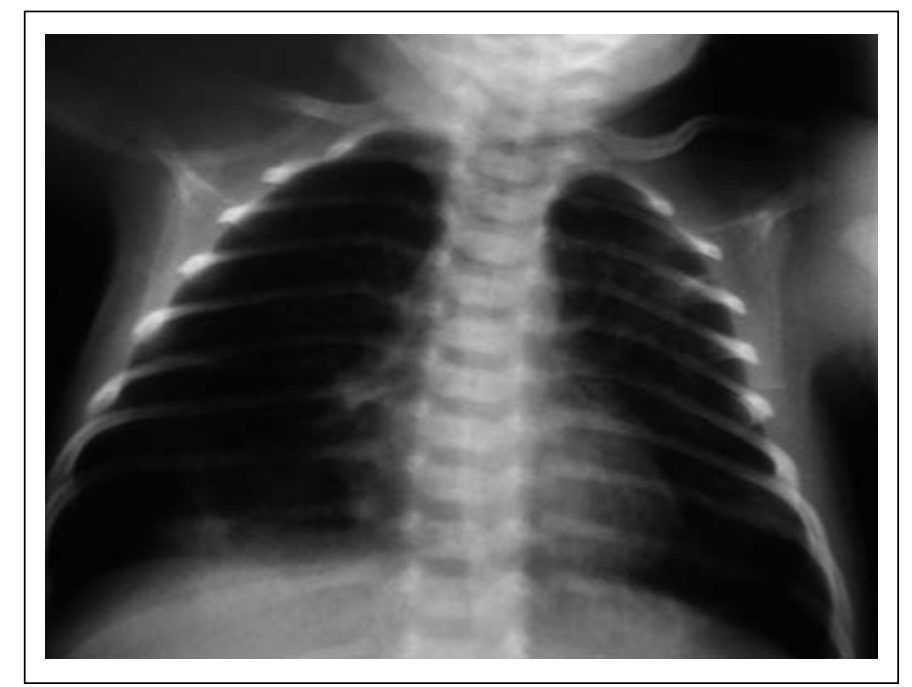

Figure 1: Chest $x$-ray on day 6 of life shows early alveolar changes and hyperinflation. 


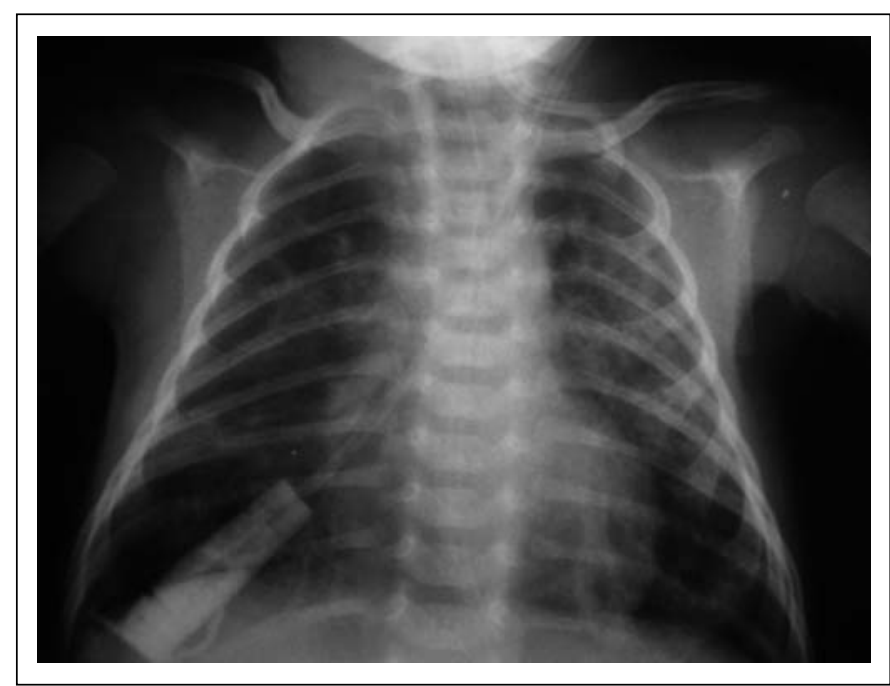

Figure 2: Shows radiographic evidence of progressive fibrosis.

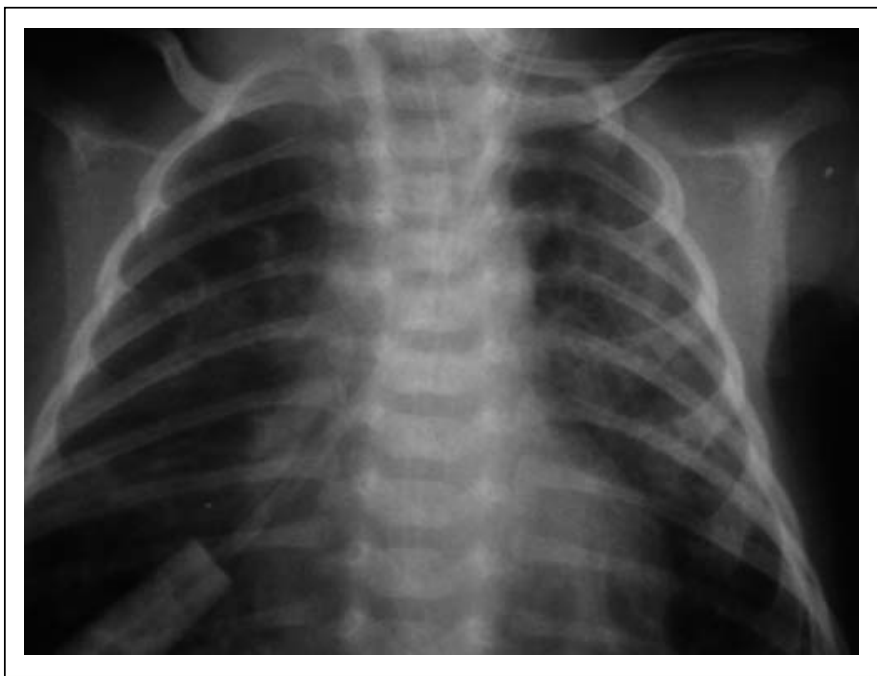

Figure 3: Chest $x$-ray before discharge (Day 22) shows residual alveolar changes and hyperinflation typical of chronic lung disease.

because of its biodegradability, rapid onset of action, and low cost. Its primary mode of action is to generate reactive oxygen radicals in the presence of light that disrupts cell membrane integrity. Once in contact with soil, it is rapidly deactivated. In humans, paraquat poisoning is often the result of intentional ingestion or occupational exposure in agricultural workers. It can cause local tissue damage and is rapidly absorbed following oral ingestion. It is distributed primarily in lungs and kidney tissues and readily crosses the placenta. Significant lung toxicity is demonstrated after the ingestion of $27-54 \mathrm{mg} / \mathrm{kg}$ of its dichloride salt. The generation of free oxygen radical causes the subsequent tissue and organ damage that is the hallmark of paraquat poisoning in humans [2].
Ingestion of paraquat during the 3rd trimester of pregnancy is often fatal to the fetus. We used the search terms paraquat, pregnancy, and fetus to perform an extensive literature review through OVID Medline ${ }^{\mathrm{TM}}$ database (Mahidol University Medical Library); the search yielded 7 reported cases of paraquat ingestion in humans during the 3rd trimester. Of the 7 reported cases, only one fetus survived. On the other hand, reports of fetal exposure to paraquat earlier in pregnancy have been more unpredictable. Musson reported on a female who ingested "a few sips" of Weedol $^{\mathrm{TM}}$ in her 20th week of gestation to deliver a term $3.36 \mathrm{~kg}$ child. However, in that case, the placenta showed signs of infarction despite the absence of toxemia or stroke. A follow up of the child at 3 years of age revealed that the child was in excellent health [3]. In other cases where exposures occurred during the first or second trimester, the patients either underwent elective abortions or the children were born too young to survive [4-6]. A clinical summary of the cases of paraquat ingestion during the 3rd trimester is provided in Table 1.

The poor outcome of paraquat ingestion during pregnancy can be explained by its pharmacokinetics and pharmacodynamics. Animal studies show that paraquat readily crosses theplacenta, where it is found in high concentrations especially in lungs, kidneys, skin, and salivary glands $[7,8]$. Moreover, it is demonstrated that type II pneumocytes in fetal rat lungs actively reuptake paraquat and cause tissue concentrations of the toxin to rise to levels found in adults by 2 weeks. In humans, development of type II pneumocytes begins at around 24 weeks gestation and continues until birth [9]. In the previously mentioned case report by Musson, the exposure to paraquat may have occurred early enough relative to the maturation of type II pnuemocytes so that pulmonary toxicity in the infant was minimal.

Effects of maternal paraquat exposure on newborn infants can be categorized into either local effects, resulting from direct exposure of the fetus to the amniotic fluid containing paraquat, or the effects resulting from the active reuptake of paraquat into tissues. Local effects include mucosal ulcerations found in the fetus as a result of swallowing amniotic fluid, as evidenced by case 6 [10-11]. Autopsy findings of the fetus also showed ulcerated lips and desquamation of the buccal mucosa, signs typically observed to result from direct ingestion of paraquat. In humans, paraquat has been shown to concentrate in the fetus at a level 4-6 times that of the mother. This is demonstrated by case 5 where the paraquat level was $5.6 \mathrm{mcg} / \mathrm{ml}$ in the mother and 20.6 $\mathrm{mcg} / \mathrm{ml}$ in the child [4] When exposure occurs later in pregnancy, the cytotoxic effects of paraquat on the fetus are evident and can range from pulmonary toxicity, such as that seen in adults, to massive hepatic necrosis in cases of massive ingestion. Talbot reported a case of paraquat ingestion during the 24th week of gestation; the infant was delivered 15 days post ingestion and expired at birth. The results of an autopsy showed fatty metamorphosis of fetal liver and heart as well as hyaline changes in the fetal lungs [4]. From such evidence (including ours), it is expected that the time of course and manifestation of organ 


\begin{tabular}{|c|c|c|c|c|c|}
\hline $\begin{array}{l}\text { Case \# and } \\
\text { Reference }\end{array}$ & $\begin{array}{l}\text { Amount } \\
\text { ingested }\end{array}$ & $\mathbf{G a}^{\mathbf{a}}$ & $\begin{array}{l}\text { Maternity } \\
\text { Urine DDTd }\end{array}$ & Maternal outcome & Fetal outcome \\
\hline \multirow[t]{3}{*}{$1^{12}$} & & 26 & Strongly positive & $\begin{array}{l}\text { Received hemoperfusion with } \\
\text { charcoal cartridge at } 4 \text { and } \\
17 \text { hour post ingestion. Pulse } \\
\text { cyclophosphamide and } \\
\text { dexamethasone started at } \\
17 \text { hours. }\end{array}$ & $\begin{array}{l}\text { NSVD } 14 \text { weeks after } \\
\text { exposure. Apgars } 1^{9} 5^{10} \text {. } \\
\text { Continued to do well at } \\
\text { 5-year follow up. }\end{array}$ \\
\hline & & & & $\begin{array}{l}\text { Developed hematemesis, anemia, } \\
\text { and renal insufficiency. }\end{array}$ & \\
\hline & & & & $\begin{array}{l}\text { Had resolution of symptoms and } \\
\text { was discharged home }\end{array}$ & \\
\hline $2^{5}$ & $1 \mathrm{tsp}$ & 28 & Not given & Died of multi-organ failure (20 days) & \\
\hline $3^{13}$ & $60 \mathrm{ml}$ & 28 & Not given & Died of multi-organ failure (17 days) & \\
\hline $4^{4}$ & $\begin{array}{l}\text { "several } \\
\text { mouthfuls" }\end{array}$ & 32 & Positive $3+$ & $\begin{array}{l}\text { Serum paraquat level } 0.85 \mathrm{mcg} / \mathrm{dL} \text {. } \\
\text { Received hemoperfusion. Died of } \\
\text { respiratory failure ( } 3 \text { days) }\end{array}$ & $\begin{array}{l}\text { Inaudible heart sound } \\
\text { ( } 3 \text { days) }\end{array}$ \\
\hline $5^{4}$ & $1 / 2$ cup & 32 & Positive $3+$ & $\begin{array}{l}\text { Developed oliguria and cyanosis. } \\
\text { Blood paraquat level } 5.6 \mathrm{mcg} / \mathrm{ml} \text {. } \\
\text { Expired }\end{array}$ & $\begin{array}{l}\text { Emergency c/s at } 4 \text { hours } \\
\text { after ingestion. Developed } \\
\text { oliguria, hypotension and } \\
\text { bradycardia at } 19 \text { hours of } \\
\text { life. Cord blood paraquat } \\
\text { level } 20.6 \mathrm{mcg} / \mathrm{ml} \text {. Expired }\end{array}$ \\
\hline $6^{11}$ & 3 mouthfuls & 36 & positive & $\begin{array}{l}\text { Died at home due to multiorgan } \\
\text { failure }\end{array}$ & $\begin{array}{l}\text { cNSVD Apgar } 4,6 \\
\text { Total exchange transfusion } \\
\text { at } 10 \text { hrs of life. Developed } \\
\text { renal failure and cyanosis } \\
\text { at } 24 \text { hours of life. Expired } \\
\text { at } 46 \text { hr of life. }\end{array}$ \\
\hline 7 (our case) & 2 mouthfuls & 36 & Not performed & $\begin{array}{l}\text { Received Dexamethasone / } \\
\text { cyclophosphamide after delivery. } \\
\text { Survived }\end{array}$ & $\begin{array}{l}\text { Emergency c/s. Apgars } 71 \text {, } \\
10^{5} \text {. Developed } \\
\text { progressive tachypnea at } \\
\text { day } 6 . \text { Survived with } \\
\text { residual lung disease }\end{array}$ \\
\hline $8^{4}$ & 3 mouthfuls & Term & Positive $3+$ & $\begin{array}{l}\text { Serum paraquat level } 1.67 \mathrm{mcg} / \mathrm{ml} \text {. } \\
\text { received hemoperfusion. Died of } \\
\text { ARDS ( } 14 \text { hours) }\end{array}$ & $\begin{array}{l}\text { Delivered via emergency } \\
\mathrm{c} / \mathrm{s}^{\mathrm{b}} \text { with Apgars of } 5^{1} \\
\text { and } 10^{3}\end{array}$ \\
\hline $\begin{array}{l}{ }^{a} G A=\text { Gestatic } \\
{ }^{b} C / S=\text { caesarec } \\
{ }^{c N S V D}=\text { Norm } \\
{ }^{d} \text { Urine DTT }=\iota\end{array}$ & $\begin{array}{l}\text { al age } \\
\text { section } \\
\text { spontaneous va } \\
\text { ne dithionite test }\end{array}$ & inal deli & & & \\
\hline
\end{tabular}

toxicity in newborn infants will closely approximate that of mothers in most cases.

Despite several case reports of paraquat ingestion during various stages of pregnancy, the management continues to be controversial. Exposures prior to the third trimester have nearly universally resulted in death of the fetus. When considering the toxicokinetics of paraquat and its ready distribution into the amniotic fluid and fetal tissue, exposure during the third trimester (especially when the pregnancy is near-term) would warrant an emergency caesarean section within a few hours of ingestion in order to prevent the local and systemic effects to the fetus. (Such was the course of action in our case). The drawback of such an approach is that the numbers of complications post-natal is inversely proportional to the infant's gestational age: we may simply be trading off risk of complications from in-utero paraquat exposure for that of Low Birth Weight newborns. This approach can only be used safely when gestational age can be reasonably confirmed to be near term. On the other hand, when immediate delivery is not a viable option and treatment is available, initiation of hemoperfusion, together with pulse cyclophosphamide/dexamethasone regimen, can result in a favorable outcome that alleviates the need for emergency caesarean section of a premature infant. 


\section{CONCLUSION}

Paraquat exposure in pregnant women carries a substantial risk of fetal as well as maternal toxicity. However, our case report suggests that prompt perinatal intervention and careful post-natal monitoring can reduce, if not eliminate, serious morbidities in the affected newborn.

The authors have no potential financial conflicts of interest to report.

\section{REFERENCES}

1. The Ramathibodi Poison Center Toxic Exposure Surveillance System Report. Bangkok: Ramathibodi Poison Center, Mahidol University; 2000-2003.

2. Tominack RL, Pond SM. Herbicides. In: Goldfrank's Toxicologic Emergencies. 7th ed. New York: McGraw-Hill; 2002:1393-410.

3. Musson FA, Porter CA. Effect of ingestion of paraquat on a 20-week gestation fetus. Postgrad Med J. 1982;58(685):

731-2.

4. Talbot AR, Fu CC, Hsieh MF. Paraquat intoxication during pregnancy: a report of 9 cases [erratum appears in Vet Hum Toxicol. Jun 1988;30(3):245]. Veterinary \& Human Toxicology. 1988;30(1):12-7.

5. Fennelly JJ, Gallagher JT, Carroll RT. Paraquat poisoning in a pregnant woman. Br Med J. 1968;3(620):722-3.
6. Raynal P, Bossard AE, Carles G. [Paraquat poisoning at the beginning of pregnancy]. Gynecologie, Obstetrique \& Fertilite 2003;31(5):449-51.

7. Ingebrigtsen K, Nafstad I, Andersen RA. Distribution and transplacental transfer of paraquat in rats and guinea-pigs. Gen Pharmacol. 1984;15(3):201-4.

8. Anderson D, McGregor DB, Purchase IF. Dominant lethal studies with paraquat and diquat in male CD-1 mice. Mutation Research. 40(4):349-58, Nov 1976.

9. Randell S, Young S. Structure of alveolar epithelial cells and the surface layer during development. In: Polin R, Fox W, eds. Fetal and neonatal physiology. Philadelphia, London, New York, St. Louis, Sydney, Tokyo: W.B. Saunders Company; 1998:1275-82.

10. Ekins B, Geller R. Paraquat and diquat. In: Ford M, Delaney K, Ling L, Erickson T, eds. Clinical Toxicology. Philadelphia, London, New York, St. Louis, Sydney, Toronto: W.B.Sauders Company; 2001:841-7.

11. Prasarnphanich T, Chinawong P, Somlaw S, Kosalwat N. Neonatal paraquat poisoning: a case report. J Med Assoc Thai. 1988;71(12):694-8.

12. Jenq CC, Wu CD, Lin JL. Mother and fetus both survive from severe paraquat intoxication. Clin Toxicol (Phila).

2005;43(4):291-5.

13. Takeuchi K, Takayama K, Tomichi N, Kan E, Yagawa K, Iwabuchi K. [Paraquat poisoning in a pregnant women (author's transl)]. Nihon Kyobu Shikkan Gakkai Zasshi Japanese Journal of Thoracic Diseases. 1980;18(10):747-52. 